\title{
COMPUTER ASSISTED LEARNING: PERCEPTION AND ACCEPTABILITY OF UNDERGRADUATE MEDICAL STUDENTS IN PHARMACOLOGY EXPERIMENTS
}

\author{
Ravi Babu K1․ A. Heraman Singh², Jayasree Palla ${ }^{3}$
}

${ }^{1}$ Associate Professor, Department of Pharmacology, GSL Medical College, Rajahmundry, E.G. District, Andhra Pradesh.

2 Professor, Department of Microbiology, GSL Medical College, Rajahmundry, E.G. District, Andhra Pradesh.

${ }^{3}$ Post Graduate, Department of Community Medicine, GSL Medical College, Rajahmundry, E.G. District, Andhra Pradesh.

\begin{abstract}
\section{BACKGROUND}

According to Medical Council of India theory and practical curriculum is very essential for all medical subjects in the undergraduate medical course in India. Animal based experimental pharmacology is still being taught in many institutions in the country, though such a practice has been abandoned at many centers. However, the use of animals in research and experimentation has been debated, defended and protested by both individuals and organizations at various levels. In recent years undergraduate training in pharmacology has been revolutionized with adoptions of new methods of teaching that focus on supportive learning through novel teaching approaches like CAL (Computer Assisted Learning).
\end{abstract}

\section{OBJECTIVE}

To assess the student's perception and acceptability of Computer Assisted Learning (CAL) as a tool in demonstrating the drug effects in animals and to analyze feedback about advantages and disadvantages of CAL software.

\section{METHODS}

CAL software was used to demonstrate action of drugs in animals. Feedback was taken from students regarding their perception, acceptability, advantages and disadvantages of this tool.

\section{RESULTS}

More than $50 \%$ of the students opined that CAL is an effective method of teaching practical aspects of pharmacology; $88.88 \%$ of students expressed that lack of interaction with living tissues and animals is the main disadvantage.

\section{CONCLUSION}

Computer Assisted Learning (CAL) is an excellent beneficial tool. It enhances the learning experience of the students and it is one of the alternative educational tools to demonstrate the drug effects in animals.

\section{KEYWORDS}

Computer Assisted Learning, Perception, Educational Tool, Adjuvant, Pharmacology Experiments.

HOW TO CITE THIS ARTICLE: Ravi Babu K, A. Heraman Singh, Jayasree Palla. "Computer Assisted Learning: Perception and Acceptability of Undergraduate Medical Students in Pharmacology Experiments." Journal of Evolution of Medical and Dental Sciences 2015; Vol. 4, Issue 102, December 21; Page: 16761-16764, DOI: 10.14260/jemds/2015/2511

\section{INTRODUCTION}

Pharmacology is a field that encompasses drug composition, properties, mechanism of action, therapeutic effects, interactions, adverse effects and contraindications of drugs. In India it is introduced in third semester to the medical students and is horizontally integrated with other paraclinical subjects like Microbiology, Pathology and forensic medicine. The training in Pharmacology takes place by way of didactic lectures, audiovisual aids and problem based learning methods using various clinical problems. The practical curriculum includes animal experiments, prescription writing and clinical problems. Pharmacology curriculum plays an integral role in medical education. ${ }^{1}$ Laboratory based practical classes have been the corner stone of undergraduate pharmacology learning.

Financial or Other, Competing Interest: None.

Submission 30-11-2015, Peer Review 01-12-2015,

Acceptance 15-12-2015, Published 19-12-2015.

Corresponding Author:

Dr. Ravi Babu K,

Associate Professor,

Department of Pharmacology,

GSL Medical College, Rajahmundry.

E-mail:drravipharma@gmail.com

DOI:10.14260/jemds/2015/2511
These classes include demonstration of drug effects on tissues or on whole animal, which has been considered as the central feature of undergraduate pharmacology learning. ${ }^{2}$ However, the use of animals in research and experimentation has been debated, defended, and protested by both individuals and organizations at various levels. The use of animals for teaching and learning of basic sciences has shown a downward trend over the last decade. ${ }^{2-4}$ Computer Assisted Learning (CAL) is a collection of experimentation on the course software package to understand the concepts and techniques. ${ }^{5}$ Laboratory based sessions are replaced by computer assisted learning, which is now being used as an effective teaching and learning tool.6,7 Several published reports from the medical schools have documented that CAL can be an effective replacement for practical sessions to overcome these limitations. Hence, the present study was done to assess the undergraduate's perception and acceptability of computer assisted learning simulations in pharmacological animal experiments.

\section{MATERIALS AND METHODS}

The study was conducted in the Department of Pharmacology, GSL Medical College, Rajahmundry, East Godavari District, Andhra Pradesh. 
After obtaining Institute Ethical Committee approval, consent was taken from all the study subjects. The questionnaire was predesigned and pretested, a pilot study was conducted on 20 students to overcome the practical difficulties and for improvement of the questionnaire. The pilot study concluded that there was no questionnaire fatigue and a good response rate provided the confidence to proceed with the study. Second MBBS students of fifth semester were included in the study, about 108 students had participated in the study. Procedures were demonstrated by using LCD projector on a large screen. All students observed the demonstrations at the same time, thereby they were sensitized with CAL software tool. The learning methodology mimicked the actual experimental set up in the laboratory.

CAL software consisted of experiments on ocular effects of miotics and mydriatics in rabbit, drug effects on ciliary motility of frog esophagus, isolated frog heart, blood pressure and heart rate of dog and bioassay of histamine on the ileum of guinea pig. The outcome in terms of perception, acceptability, advantages and disadvantages of CAL as an educational tool was assessed by questionnaire method. The questionnaire consisted of closed type questions (Yes or No, agree or disagree). The questionnaire was given to each of the participant and they were asked to tick the option. Students were instructed not to reveal their identity in the questionnaire form. The completed questionnaires were collected and analyzed in percentages.

\section{RESULTS}

The present study results showed that CAL software tool in pharmacology animal experiments was strongly accepted by more than $50 \%$ of the students and learning objective was achieved; $88.88 \%$ of the students had opined that animal utility has to be avoided. Majority also expressed that there is clear visualization of drug effects and more chance of reproducibility (Fig-1). Regarding disadvantages, majority opined that there is lack of interaction with live tissues and animals (Fig-2). On the whole $84.25 \%$ of students expressed that CAL should be conducted as an adjuvant learning method prior to practicals (Table 1).

\section{DISCUSSION}

In the medical education curriculum of undergraduate teaching, animal experiments in pharmacology play a vital role in demonstrating the mechanism of drug actions. Now-a-days it has become steadily more difficult to perform animal experiments, because of issues related to the procurement of animals, their cost and regulations controlling their use and changes in ethical issues towards animal experimentation in general. The debate on utilization of animals in experiments and teaching started way back in the $17^{\text {th }}$ century. In $18^{\text {th }}$ century, the animal protection movement was started by a group of people known as abolitionists in England. ${ }^{8}$ In the year 1982, the prevention of cruelty to animals (PCA) Act 1960 was amended in India. ${ }^{9}$

For this purpose, the Government of India has formulated "Breeding of and experiments on animals (Control and Supervision) Rules, 1998" as amended during 2001 and 2006 to regulate the experimentation on animals. The CPCSEA provides guidelines for performing experiments on animals and maintenance of animal house. ${ }^{10}$
As per CPCSEA guidelines amendment in 2006, a separate permission from CPCSEA is required to carry out any experiments on these large animals. However, the Institutional Animal Ethics Committee (IAEC) of the respective establishments is empowered to permit experiments on small animals. ${ }^{11,12}$ In India, animals are used in pharmacology for undergraduate teaching to demonstrate the effects of various drugs, although this has been phased out in most of the institutes. Typical experiments include effect of drugs on intestine, eye, central nervous system and reproductive system of rabbit and also on the frog's heart and rectus. The later experiments had however declined due to ban on use of frogs. ${ }^{13-15}$ For postgraduate teaching also animals were used to demonstrate the effects of various drugs, to determine the nature of an unknown drug for bioassay, for screening methods and to learn skills like how to administer drugs in animals.

In this aspect there has been a concern about continuing the animal experiments in the postgraduate courses, but the rules and guidelines are confusing and unclear. ${ }^{16}$ The disadvantage associated with animal experiments is lack of reproducibility and variations in biological responses. These experiments have several limitations which include pain, distress and unethical behaviour to animals, requirement of skilled manpower, availability, purchase and maintenance cost of the animals. In addition time consuming protocols and difficulty in handling large animals were also the problems to be faced. Although, no data is available from India, most medical colleges have begun using or implementing alternatives to animal experiments in undergraduate courses. ${ }^{13,17,18}$ In this scenario CAL (Computer Assisted Learning) software proves to be a milestone in pharmacological teaching in demonstrating animal experiments.

Recognizing its importance in medical education, it was also encouraged by Medical Council of India (MCI) as an alternative to live animal experiments. The proposed new curriculum of MCI "Vision-2015" for undergraduates might make it mandatory to have simulation labs for alternatives. ${ }^{19}$ Computer based simulations provide practice-oriented tasks building on student's theoretical knowledge. They provide a good opportunity for the student to repeat the simulated experiment and rehearse the information which improves retention.

It facilitates the student to learn at his/her own pace, pause, repeat and resume the steps for studying the responses to a particular drug. The greatest advantage is improvement in learning ability of slow learners. CAL increases the understanding of the theoretical concepts when it is applied in the setting of simulated experiments. ${ }^{20}$ This learning process has an added advantage of preventing the unethical killing of animals. There is no need for handling of live animals, dissection and isolation of tissues, administration of drugs and also no question of ADRs and behavioral changes of animals during the experiment like irritation, aggressiveness and animal bites. In computer-assisted learning also, there are certain limitations like technical and imaginative boundaries.

The technical limitation includes standardization of CAL software tool through an expert group and involvement of skilled teaching faculty in medical colleges. In the current study, $65.74 \%$ of students responded that they have achieved the learning objectives. 
Similar findings were reported by a study conducted by Govindaraja C et al., emphasizing that $70 \%$ of students had achieved learning objectives. ${ }^{21}$ regarding students response about their understanding on computer simulation experiment, $58.33 \%$ of students opined positively. In contrast to this, a previous study. ${ }^{21}$ reported that $3 / 4^{\text {th }}$ of the students opined positively (75\%). The present study expressed clearly that more than $50 \%$ of students accepted CAL as one of the effective methods in animal experimentations. A study. ${ }^{22}$ conducted in India on the use of CAL, showed that $87 \%$ opted CAL as an adjuvant to practicals, correlating well with the present study. This methodology may be encountered with resistance and challenges at multiple stages which include difficulties at the academic, administrative, financial and logistics level. Appropriate software programs need to be developed based on the learning objectives and the programs should be modified to meet the local educational needs. CAL is expensive in the initial stages of implementation in the curriculum. ${ }^{23}$ It has to be recognized that without strategic planning, financial resources and active promotion of multidisciplinary working we cannot potentiate the teaching and learning standards.

\section{CONCLUSION}

Computer Assisted Learning (CAL) is an excellent beneficial tool. It enhances the learning experience of the students and is an effective adjuvant educational tool to demonstrate the drug effects on living tissues and animals. CAL like technologies may not replace animal experiments rather they enhance learning ability as an adjuvant to animal experiments.

\section{ACKNOWLEDGEMENT}

The authors are highly indebted to Dr. YV Sharma, Principal, Dr. DS Swaroop, Executive Officer for permitting to use the facilities for projection and also thankful to fifth semester medical students of GSL Medical College for their participation in the study.

\section{REFERENCES}

1. Amberkar M, Mohan L, Kumari M, et al. A survey on methods of undergraduate pharmacology teaching. JPRHC, 2011;3(2), pp 43-49.

2. Kuruvilla A, Ramalingam S, Bose AC, Shastri GV, Bhuvaneswari K, Amudha G. Use of computer assisted learning as an adjuvant to practical pharmacology teaching: Advantages and limitations. Indian J Pharmacol. 2001;33:272-5.

3. Greenhalgh T. Computer assisted learning in undergraduate medical education. BMJ 2001;322:40-4.

4. Hansen LA, Boss GR. Use of live animals in the curricula of US Medical Schools: Survey results from 2001. Acad Med 2002;77:1147-9.

5. Baby LT, Kavalakkat JC, Abraham S, et al. CAL: A modern tool for Pharmacology. Internet J of Medical Simulation. 2009;2:2.

6. Wiecha JM. Collaborative Online Learning (COL): A new distance education methods. Essential Drug Monitor. 2003;33:36.

7. Moss S. Computer technology in education. Pharm J 1993;251:491
8. Richmond J. Refinement, reduction and replacement of animal use for regulatory testing: future improvements and implementation within the regulatory framework. ILAR J 2002;43:S63-8.

9. The prevention of cruelty to animals act as amended by Central Act 26 of 1982. Available from: http://www.moef.nic.in/legis/awbi/awbi01.html [Last accessed on 2015 Nov 24].

10. Committee for the purpose of control and supervision of experiments on animals (CPCSEA). Available from: http://cpcsea.nic.in/Content/54_1_ACTSANDRULES.aspx [Last accessed on 2015 Nov 25].

11. Committee for the purpose of control and supervision of experiments on animals (CPCSEA). Available from: http://cpcsea.nic.in/Content/55_1_GUIDELINES.aspx [Last accessed on 2015 Nov 25].

12. The recommendations of the sub-committee on rehabilitation of animals after experimentation set up by CPCSEA, 2006. Available from: http://www.moef.nic.in/sites/default/files/SOP_CPCSEA_ inner_page \%20\%281\%29.pdf [Last accessed on 2015 Nov 25].

13. Badyal DK, Modgill V, Kaur J. Computer simulation models are implementable as replacements for animal experiments. Altern Lab Anim 2009;37:191-5.

14. Regulations on graduate medical education, 1997 (Amended upto 2010). Medical Council of India. Available from: http://www.mciindia.org/Rules-andRegulation/GME_REGULATIONS.pdf [Last accessed on 2015 Nov 22].

15. Badyal D. Practical manual of Pharmacology. 1st ed. New Delhi: Jaypee Publishers; 2008. p. 73-93.

16. Postgraduate medical education regulations, 2000 (Amended upto 2012). Medical Council of India. Available from: http://www.mciindia.org/Rules-andRegulation/GME_REGULATIONS.pdf [Last accessed on 2015 Nov 23].

17. Badyal DK, Bala S, Kathuria P. Student evaluation of teaching and assessment methods in pharmacology. Indian J Pharmacol 2010;42:86-8.

18. Mohammad AA, Mohammed Z, Karukayil JM. Alternatives to animals in education, research and risk assessment: An overview with special reference to Indian context. ALTEX 2013; 2:5-19.

19. Vision 2015, Medical Council of India. Available from: http://www.mciindia.org/tools/announcement/MCI_boo klet.pdf [Last accessed on 2015 Nov 26].

20. Sewell RD, Stevens RG, Lewis DJ. Pharmacology experimental benefits from the use of computer assisted learning. Am J Pharm Educ 1996;60:303-7.

21. Govindaraja C, Jaiprakash $\mathrm{H}$, Annamalai C, et al. Computer assisted learning: Perceptions and knowledge skills of undergraduate medical students in a Malaysian Medical School. Natl J Physiol Pharm Pharmacol 2011;1:63-7.

22. Kuruvilla et al. Use of computer assisted learning as an adjuvant to practical pharmacology teaching: advantages and limitations. Indian Journal of Pharmacology 2001;33:272-275.

23. Lisha J John. A review of computer assisted learning in medical undergraduates. J Pharmacol Pharmacother. 2013 Apr-Jun;4(2):86-90. 


\begin{tabular}{|l|c|}
\hline & Yes (\%) \\
\hline Simulations were excellent & 61.11 \\
\hline My learning objectives were achieved & 65.74 \\
\hline I had a clear understanding after computer simulation experiment & 58.33 \\
\hline I enjoyed this learning method & 61.11 \\
\hline Computer simulation experiment did not help me in learning aspects & 44.44 \\
\hline I prefer current simulations to live animal experiments & 47.22 \\
\hline The displayed instructions were useful to me & 87.03 \\
\hline CAL is an effective method of teaching practical aspects & 50.92 \\
\hline CAL should be conducted as an adjuvant to practicals & 84.25 \\
\hline CAL is a welcome change to routine practicals & 62.03 \\
\hline Effects of drugs demonstrated on animals are interesting & 69.44 \\
\hline Many experiments can be demonstrated in a short time & 75.92 \\
\hline Laboratory practical allowed me to learn more than computer simulation & 43.51 \\
\hline \multicolumn{2}{|c|}{ Table 1: Feedback of students on computer-simulated pharmacology experiments } \\
\hline
\end{tabular}

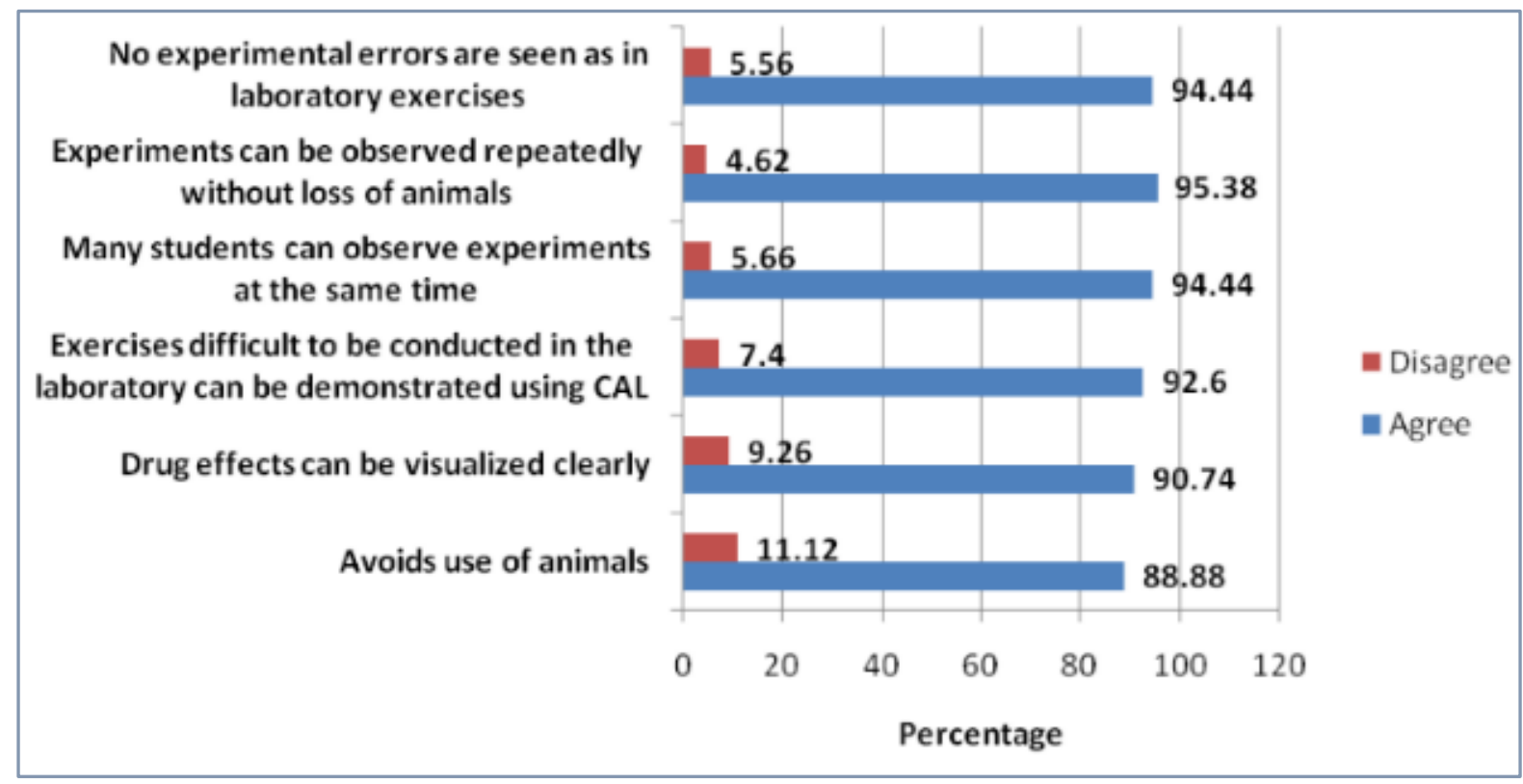

Fig. 1: Opinion on Advantages of Using Cal in Pharmacology Experiments

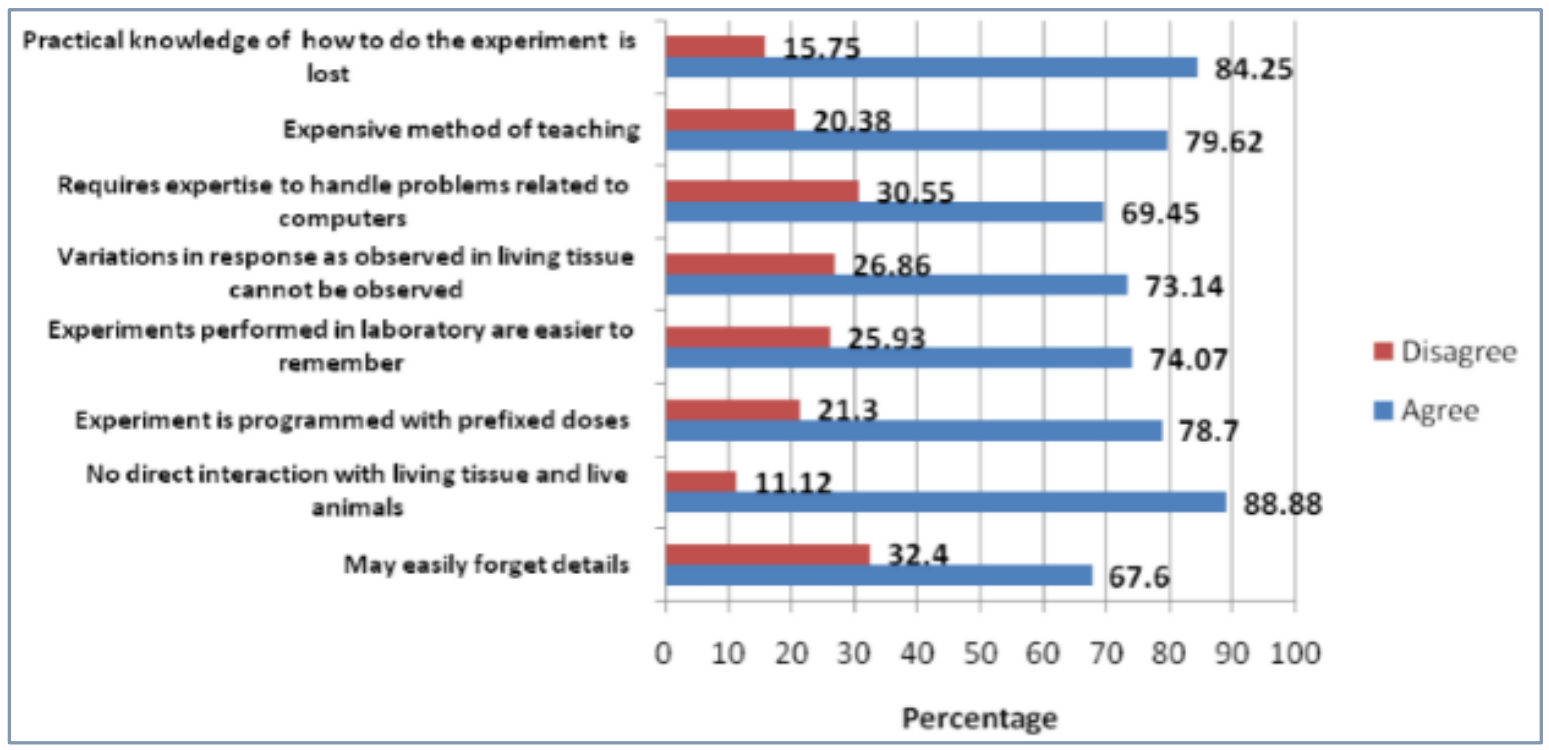

Fig. 2: Opinion on Disadvantages of Using Cal in Pharmacology Experiments 